\title{
NON-SYNCHRONISED MITOSIS IN A COMMON CYTOPLASM
}

\author{
ASHRAFUL HAQUE \\ John Innes Horticultural Institution \\ Department of Botany, University of Oxford
}

Received 10.xii.52

During the course of some X-ray experiments with a clone of Professor Karl Sax's Tradescantiaz paludosa $(2 n=12)$, a control preparation of the first pollen grain mitosis showed an interesting abnormality. Along with the normal pollen grains containing the single "primary" nucleus, a large number contained two "primary" haploid nuclei. These were not the generative and vegetative nuclei since such pollen had not yet undergone any mitosis.

The presence of binucleate pollen in itself is nothing very astonishing. No doubt it arose by the complete suppression of the wall formation after the second meiotic division which would thus end in two dyads with two nuclei in each, instead of the normal tetrad containing four cells with a single nucleus in each. As expected the abnormal pollen was twice the size of the normal. The sample showed a large number of the abnormal cells undergoing first pollen mitosis and these cells clearly fell under two classes.

Only one anther was involved and even in this the abnormality was manifest only in a single lobe-the other being perfectly normal. That the abnormality was present in only one half of a single anther indeed requires the assumption of somatic mutation.

Synchronised mitosis.-In some pollen grains both the primary nuclei at any time are at exactly the same developmental stage (plate, fig. I). This is similar to the findings of Barber (I94I) and Sax (1942) on the attached pollen grains of Uvularia and Tradescantia. It also agrees with my own observations on attached and binucleate pollen in $T$. bracteata induced by different degrees of suppression of the wall formation by X-rays (Haque, I952). The two nuclei in such cases usually complete mitosis separately to form two generative and two vegetative nuclei (plate, fig. 2). Occasionally, however, each nucleus may begin as an independent unit but, as metaphase is reached, only one plate develops : all the twelve chromosomes, six from each nucleus, then make use of the same spindle. This naturally gives a single generative and vegetative nucleus, both of which are therefore diploid.

Non-synchronised mitosis.-In a considerable number of cells, however, the development of the two nuclei was not synchronised (table and figs. 3-6). 


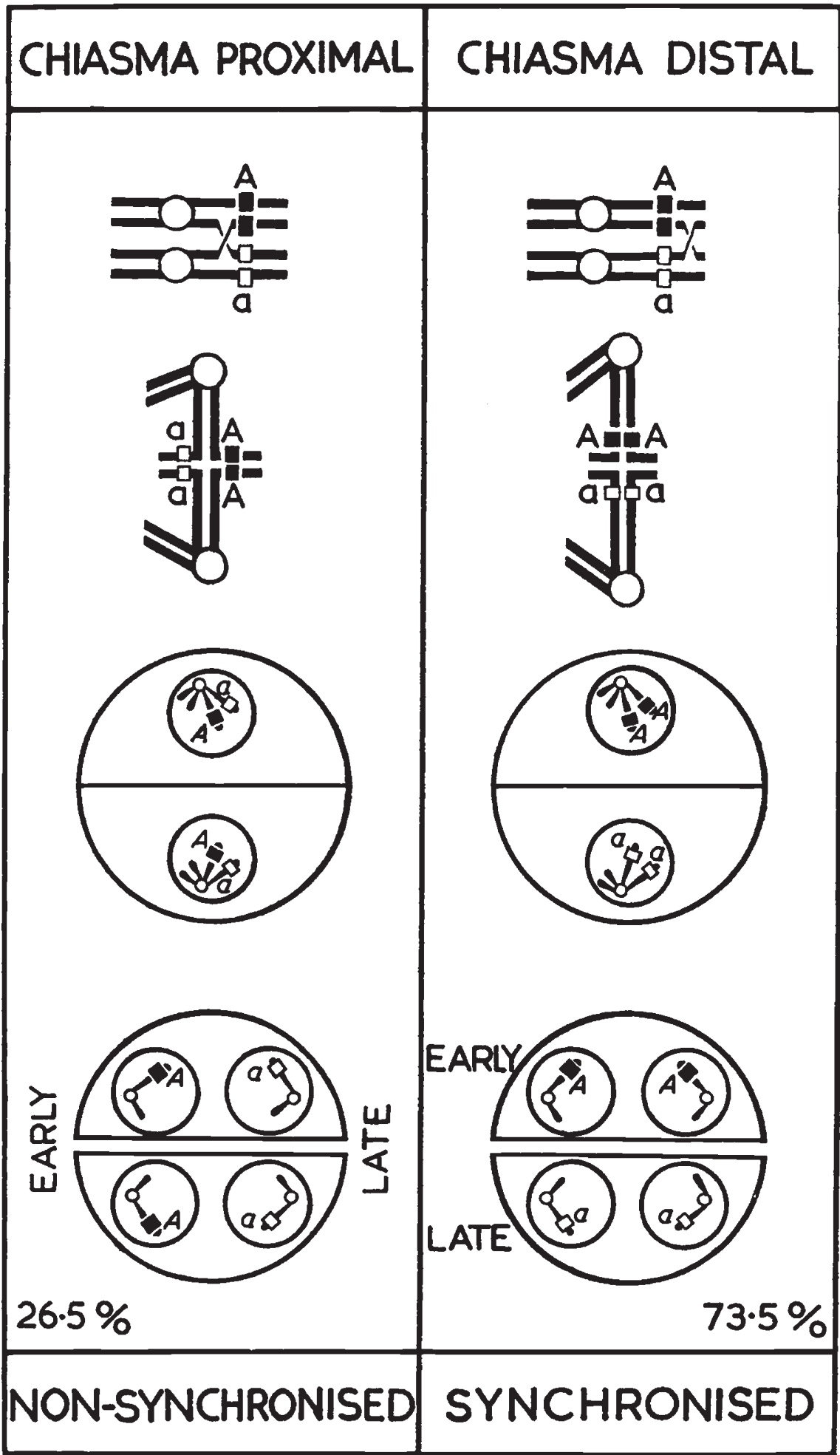

FIG. 1.-Origin of synchronised and non-synchronised mitosis in the binucleate pollen grains of $T$. palusosa. 
Barber (I94I) found that sometimes, after induced meiotic abnormality, tetrads are formed where one cell contains extra chromosomes missing from its sister cell. The one with the accessory chromosomes rarely survived, the deficient one never. However, when the wall between the two was not formed, or only partly formed, both survived and the mitosis was always synchronised. This is due to cooperation between the two nuclei brought about by the flow of material from one to the other through the cytoplasm. Darlington and Mather (1949) point out that this cooperation takes place, only, if both the nuclei are equally fit or equally unfit.

TABLE

The proportion of the various classes of pollen grains in the affected anther lobe

\begin{tabular}{|c|c|c|c|c|}
\hline $\begin{array}{c}\text { Total no. } \\
\text { (all classes) }\end{array}$ & $\begin{array}{c}\text { Uninucleate pollen } \\
\text { (normals) }\end{array}$ & \multicolumn{3}{|c|}{$\begin{array}{c}\text { Binucleate pollen } \\
\text { (abnormals) }\end{array}$} \\
\hline 1240 & 771 & \multicolumn{2}{|c|}{469} \\
\hline & \multicolumn{2}{|c|}{$\begin{array}{c}\text { Non- } \\
\text { Total no. } \\
\text { in mitosis }\end{array}$} & Synchronised & $\begin{array}{c}\text { Nonnchronised } \\
\text { synch }\end{array}$ \\
\hline 87 & 64 & 23 \\
\hline
\end{tabular}

In the present case there is no visible difference in the chromosome complement of the nuclei involved and yet some cells show synchronisation while the others do not. The dyad occurs in groups of pollen grains. The non-synchronisation is fairly evenly distributed within these groups. The synchronised and non-synchronised mitosis could be explained by assuming that this plant is heterozygous (fig. r) for a gene $(A)$ controlling the threshold for mitosis. If the gene in question is 26.5 cross-over units from the centromere, then in 26.5 per cent. of the dyads the two nuclei will have the genic constitutions $A$ and $a$. In the remainder (73.5 per cent.) there being no crossingover between the $A$ locus and the centromere, there will not be any segregation at the second division. Thus the two nuclei in each dyad will be either $A$ or $a$. Where pollen grains have the two nuclei $A$ and $a$ synchronisation will fail.

Having only half an anther for study I was not able to show that $A A$ and $a a$ dyad pollen grain divide at different times.

\section{REFERENCES}

BARBER, H. N. 1941. Chromosome behaviour in Uvularia. 7. Genet., 42, 223-257. DARLington, C. D., AND MATHER, K. 1949. The Elements of Genetics. London : Allen \& Unwin. HAQUE, A. 1952. Irradiation of Meiosis in Tradescantia. (In the press.) SAX, x. 1942. Diffusion of gene products. Genetics, 28, 303-306. 
Illustrating synchronised and non-synchronised rst pollen mitosis in binucleate pollen of $T$. paludosa. Feulgen smear. All figures $\times 175^{\circ}$.

Fig. 1.-A binucleate pollen grain. Both the nuclei are perfectly synchronised and show late prophase of the ist pollen grain mitosis.

Fig. 2.- Two generative (small and densely stained) and two vegetative (large and lightly stained, one superimposed) nuclei as a result of the ist pollen grain mitosis in a binucleate polleu grain.

Fig. 3.-Non-synchronisation. One nucleus has reached prometaphase while the accompanying one is at early prophase.

Fig. 4.-One nucleus has completed mitosis forming a generative and a vegetative nucleus while the other has as yet only reached metaphase.

Fig. 5.-One nucleus showing prometaphase while the other is still inactive.

FIG. 6.-One nucleus showing metaphase while the other is still inactive. 


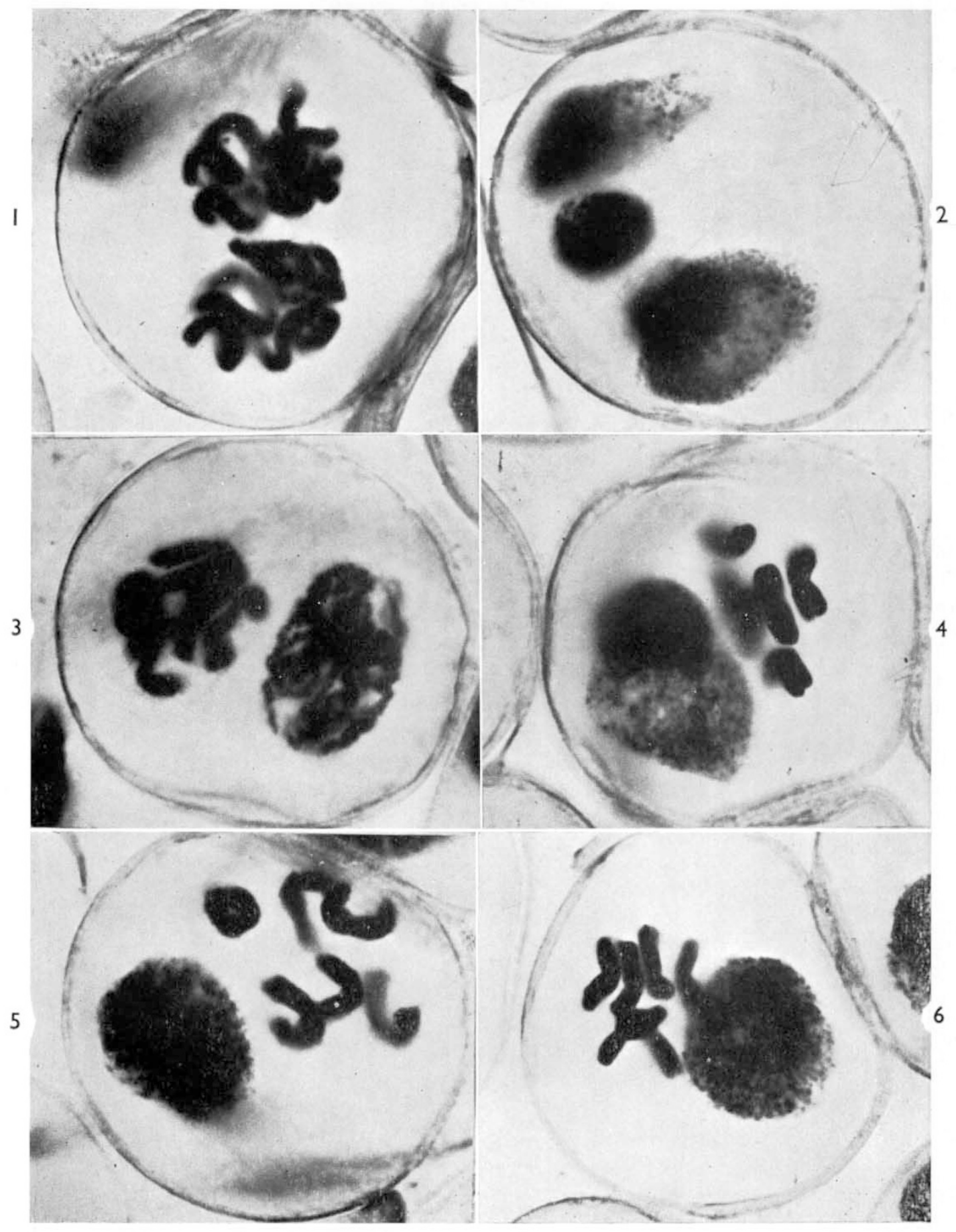

